\title{
Physical, Magnetic and Electrical Properties of Ga Substituted Mn-Ferrites
}

\author{
A. A. Sattar \\ Physics Department, Faculty of Science, Ain Shams University, Cairo, \\ Egypt
}

Samples with the chemical formula $\mathrm{MnGa}_{x} \mathrm{Fe}_{2-x} \mathrm{O}_{4}(x=0.0,0.1,0.3,0.5$ and 0.7$)$ were prepared by the usual ceramic method. $X$-ray analysis revealed the presence of single spinel phase. The lattice parameters as well as the porosity were found to decrease while the density and grain size were increased with increasing $G a$ concentration (x). The magnetization, the initial permeability and Curie temperature are decreased with increasing $x$. On the other hand, the dc electrical resistivity is increased with increasing $G a$ concentration. The results are explained according to the assumed cation distribution.

\section{Introduction:}

Spinel ferrite is one of the most important classes of magnetic ceramic materials owing to their interesting applications. In the spinel structure, the magnetic ions are distributed among two different lattice sites, tetrahedral (A) and octahedral (B) sites. The magnetic as well as the electrical properties of these ferrites depend on the relative distribution of cations at the different sites as well as the preparation condition [1]. The magnetization of either site can be reduced relative to the other one by substitution of non magnetic ions in the corresponding sites. In $\mathrm{Al}^{3+}$ substituted ferrites, the $\mathrm{Al}^{3+}$ ions occupy the B-sites while in $\mathrm{In}^{3+}$ substituted ferrites, the $\mathrm{In}^{3+}$ ions occupy the A-sites [2]. The situation seems to be not so clear in case of $\mathrm{Ga}^{3+}$ substituted ferrites. Maxwell et al [3] studied the system of $\mathrm{NiGa}_{\mathrm{x}} \mathrm{Fe}_{2-\mathrm{x}} \mathrm{O}_{4}$ and found that the magnetization increased with increasing Ga concentration up to $\mathrm{x}=0.63$. Further increase of $\mathrm{x}$ leads the magnetization to decrease. They concluded that $\mathrm{Ga}$ ions prefer to occupy the A-sites for $x \leq 0.63$. On the other hand, Quintanar et al. [4],using Mössbauer spectra, showed that in the same system, $\mathrm{NiGa}_{x} \mathrm{Fe}_{2-\mathrm{x}} \mathrm{O}_{4}$, not all the $\mathrm{Ga}^{3+}$ ions entered into the A-sites. Moreover, the cation distribution in $\mathrm{Ga}$ substituted magnetite, $\mathrm{Fe}_{3-\mathrm{x}} \mathrm{Ga}_{\mathrm{x}} \mathrm{O}_{4}$, was investigated by Dehe et al [5]. They concluded that for $\mathrm{x} \leq 0.3, \mathrm{Ga}^{3+}$ ions are located in the tetrahedral (A) sites only. 
For $\mathrm{x}>0.3, \mathrm{Ga}^{3+}$ ions begin to distribute between the tetrahedral and octahedral sites. However, Rosenberg et al [6] found that in Ga substituted magnetite, $\mathrm{Ga}^{3+}$ ions distribute on both $\mathrm{A}$ and $\mathrm{B}$-sites even at very low $\mathrm{Ga}$ concentration. Furthermore, the system $\mathrm{CdGa}_{\mathrm{x}} \mathrm{Fe}_{2-\mathrm{x}} \mathrm{O}_{4}$ was investigated using IR and Mössbauer [7] and the results showed that due to the high preference of $\mathrm{Cd}$ ions to occupy the A sites, $\mathrm{Ga}^{3+}$ ions substitute the $\mathrm{Fe}^{3+}$ ions at the $\mathrm{B}$-sites only.

It is seen that the above studied $\mathrm{Ga}$ substituted ferrites are either inverse spinel, $\mathrm{NiFe}_{2} \mathrm{O}_{4}$ and $\mathrm{Fe}_{3} \mathrm{O}_{4}$ or normal spinel, $\mathrm{CdFe}_{2} \mathrm{O}_{4}$. The $\mathrm{MnFe}_{2} \mathrm{O}_{4}$ has a structure which is neither inverse nor normal but it is partially normal spinel ferrite with a cation distribution given by [1] $\left(\mathrm{Mn}_{0.8} \mathrm{Fe}_{0.2}\right)\left[\mathrm{Mn}_{0.2} \mathrm{Fe}_{1.8}\right] \mathrm{O}_{4}$, where the brackets ( ) and [ ] denote the A and B sites, respectively. It is clear that, there will be a competition between $\mathrm{Fe}$ and Ga ions to occupy the A-sites in the system $\mathrm{MnGa}_{x} \mathrm{Fe}_{2-\mathrm{x}} \mathrm{O}_{4}$. The resultant cation distribution will affect the magnetic as well as the electrical properties. Therefore, we aimed to study the physical, magnetic and electrical properties of the system $\mathrm{MnGa}_{\mathrm{x}} \mathrm{Fe}_{2-\mathrm{x}} \mathrm{O}_{4}$. The measured parameters are the lattice constants, density, porosity, magnetization, initial permeability and electrical resistivity.

\section{Experimental techniques:}

Samples of the chemical formula $\mathrm{MnGa}_{\mathrm{x}} \mathrm{Fe}_{2-\mathrm{x}} \mathrm{O}_{4}(\mathrm{x}=0.0,0.1,0.3,0.5$ and 0.7 ) were prepared by the usual ceramic technique. High purity oxides, $99.9 \%$, were dried and mixed according to their molecular weight. The powders were presintered at $900^{\circ} \mathrm{C}$ for $12 \mathrm{hr}$ followed by a slow cooling and were ground again to fine powders using an agate mortar grinder RM100. Two shaped samples, toroids and discs, were pressed out of the presintered powders at a pressure of $3 \times 10^{8} \mathrm{~Pa}$ and were finally sintered at $1300^{\circ} \mathrm{C}$ for $3 \mathrm{hr}$. The samples were slowly cooled in $\mathrm{N}_{2}$ down to room temperature. X-ray diffraction patterns were recorded using Philips diffractometer (type X'pert-MPD system) with $\mathrm{CuK}_{\alpha}$ radiation. The apparent density $\rho$ of the samples was measured using Archimed's principle. Polished and etched samples, using boiling $\mathrm{HCl}$, were used to observe the microstructure using a scanning electron microscope (SEM) (type JEOL JEM-1200 EXII). The toroidal samples with outer diameter $1.5 \mathrm{~cm}$ and inner diameter $0.8 \mathrm{~cm}$ were used as transformer cores for measuring both the magnetization $\mathrm{M}(\mathrm{A} / \mathrm{m})$ and initial permeability $\mu_{\mathrm{i}}$. These measurements are based simply on Faraday's law of induction. The magnetization was measured at the room temperature in a magnetic field up to $2500 \mathrm{~A} / \mathrm{m}$ The initial permeability was measured as a function of temperature at a constant magnetizing current $\approx 3 \mathrm{~mA}$ and a constant frequency $\mathrm{f}=10 \mathrm{kHz}$. The value of $\mu_{\mathrm{i}}$ was calculated using Poltinnikov's formula [8] which is given by $\mathrm{V}_{\mathrm{s}}=K \mu_{\mathrm{i}}$ where $\mathrm{V}_{\mathrm{s}}$ is the induced voltage in the secondary coil and $K$ is a constant which 
depends on the magnetizing current, frequency, number of turns of the primary and secondary coils and the dimensions of the sample. Disc shaped samples with diameter $9 \mathrm{~mm}$ and an average thickness of $3 \mathrm{~mm}$ were used for the electrical resistivity measurements. The electrical resistivity was measured by the two electrode method with $\mathrm{In}-\mathrm{Hg}$ used as a contact material, taking into consideration that the current passing through the sample does not exceed 10 $\mathrm{mA}$ to avoid the Joule heating effect. The temperature was measured using Ktype thermocouple.

\section{Results and discussion}

\section{3-1. Crystallographic}

$\mathrm{X}$-ray diffraction patterns showed that all investigated samples are formed in a single cubic spinel phase. The d-spacing for each peak was recorded automatically and the experimental lattice parameter, $\mathrm{a}_{\exp }$ is calculated from the relation

$$
\mathrm{a}_{\mathrm{exp}}=\mathrm{d}_{\mathrm{hkl}}\left[\mathrm{h}^{2}+\mathrm{k}^{2}+\mathrm{l}^{2}\right]^{1 / 2}
$$

The values of the lattice parameters obtained for each reflected plane are plotted against the function $\mathrm{F}(\theta)=1 / 2\left[\cos ^{2} \theta / \sin \theta+\cos ^{2} \theta / \theta\right]$, where $\theta$ is the Bragg's angle and straight lines are obtained as shown in Fig.(1). The accurate values $\mathrm{a}_{\mathrm{o}}$ were estimated from the extrapolation of these lines to $F(\theta)=0$. The values of the experimental lattice parameters for the different $\mathrm{Ga}$ concentration (x) are given in Table (1).

Table (1): Variation of experimental lattice parameter $a_{0}$, X-ray density $\rho_{x}$ apparent density $\rho$ and porosity $\mathrm{P} \%$ with the Ga concentration x. $\delta$ and $\mathrm{t}$ are the $\mathrm{Fe}^{2+}$ and $\mathrm{Ga}^{3+}$ concentration on B-sites.

\begin{tabular}{|l|l|c|c|c|c|c|}
\hline $\mathrm{X}$ & \multicolumn{1}{|c|}{$\mathrm{a}_{\mathrm{o}}(\AA)$} & $\delta$ & $\mathrm{t}$ & $\rho_{\mathrm{x}}\left(\mathrm{g} / \mathrm{cm}^{3}\right)$ & $\rho\left(\mathrm{g} / \mathrm{cm}^{3}\right)$ & $\mathrm{P}(\%)$ \\
\hline 0 & 8.5133 & 0.15 & 0.0 & 4.9647 & 4.6630 & 6.077 \\
0.1 & 8.5240 & 0.12 & 0.065 & 4.9758 & 4.8196 & 3.139 \\
0.3 & $8.5087(5)$ & 0.10 & 0.20 & 5.0625 & 4.8730 & 3.743 \\
0.5 & $8.4909(2)$ & 0.08 & 0.35 & 5.1547 & 4.8780 & 5.367 \\
0.7 & $8.4781(6)$ & 0.02 & 0.55 & 5.2424 & 4.9540 & 5.500 \\
\hline
\end{tabular}




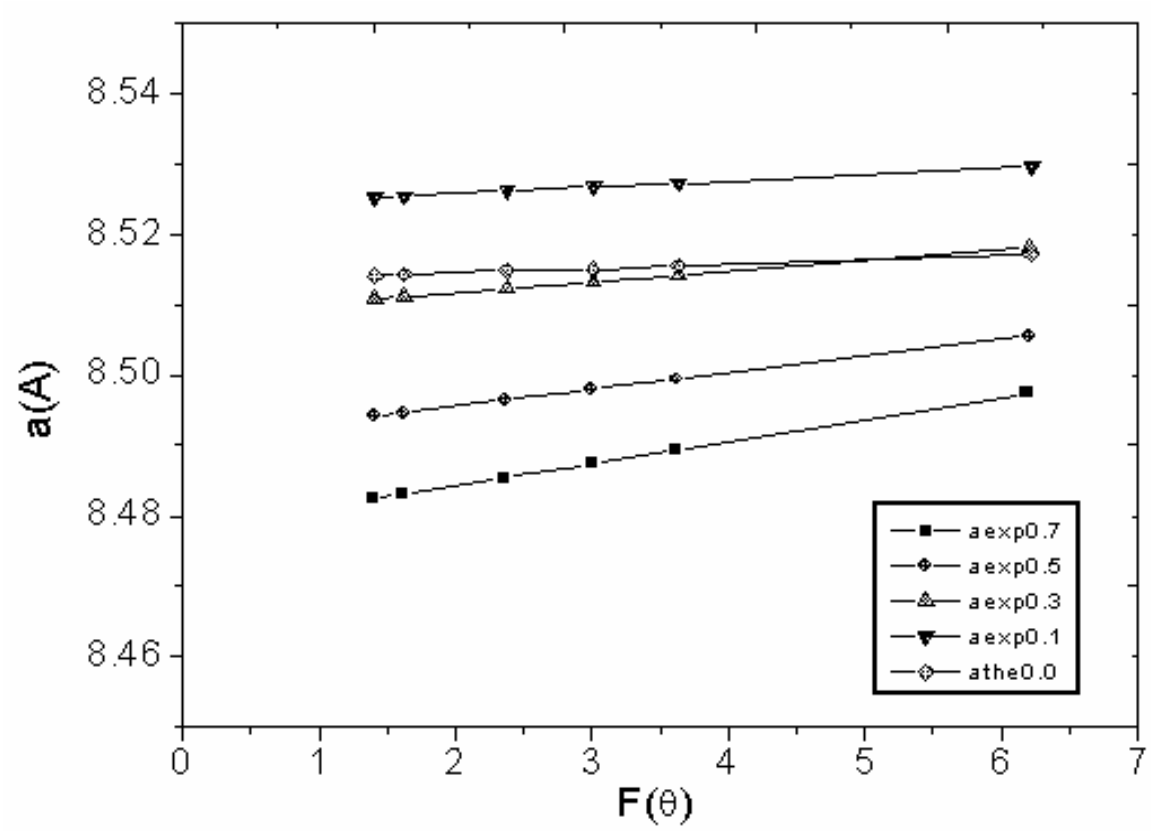

Fig. (1): Variation of $a_{\exp }$ with $F(\theta)$

One may notice that, the lattice parameter is slightly decreased with increasing $\mathrm{x}$. It is due to the fact that the radius of the $\mathrm{Ga}^{3+}$ ion $(0.62 \AA)$ is smaller than that of $\mathrm{Fe}^{3+}$ ion $(0.645 \AA)$ [Goldschmidt ionic radii]. One also notices that there is a good agreement between the obtained lattice parameter value $(8.513 \AA)$ and that reported by JCPDS cards $(8.515 \AA)$ for the sample with $\mathrm{x}=0$ i.e. $\mathrm{MnFe}_{2} \mathrm{O}_{4}$.

The theoretical lattice parameter $\mathrm{a}_{\mathrm{th}}$ of the investigated samples is calculated from the equation [9]

$$
a_{\text {th }}=\frac{8}{3 \sqrt{3}}\left[\left(\mathrm{r}_{\mathrm{A}}+\mathrm{R}_{\mathrm{o}}\right)+\sqrt{3}\left(\mathrm{r}_{\mathrm{B}}+\mathrm{R}_{\mathrm{o}}\right)\right]
$$

where $R_{o}$ is the radius of the oxygen ion $(1.32 \AA), r_{A}$ and $r_{B}$ are the ionic radii of the tetrahedral and octahedral sites respectively. To calculate $r_{A}$ and $r_{B}$, different factors concerning the cation distribution were taken into consideration:

1- It was reported that the manganese ferrite is nearly normal than inverted spinel with about 0.8 tetrahedral sites occupied by manganese $[1,10]$.

2- During the sintering process, oxygen loss occurs leading a part of $\mathrm{Fe}^{3+}$ ions transforms to $\mathrm{Fe}^{2+}$ for charge compensation [11]. 
3- It is assumed that the $\mathrm{Ga}^{3+}$ ions are distributed between the tetrahedral and octahedral sites. Taking these facts into consideration, the general cation distribution is suggested to be :

$$
\left(\mathrm{M}_{0.8}^{2+} \mathrm{Ga}_{\mathrm{x}-\mathrm{t}}^{3+} \mathrm{Fe}_{0.2-\mathrm{x}+\mathrm{t}}^{3+}\right)\left[\mathrm{Mn}_{0.2}^{2+} \mathrm{Ga}_{\mathrm{t}}^{3+} \mathrm{Fe}_{\delta}^{2+} \mathrm{Fe}_{1.8-\mathrm{t}-\delta}^{3+}\right] \mathrm{O}_{4-\delta / 2}^{2-}
$$

where $\mathrm{t}$ and $\delta$ are the $\mathrm{Ga}^{3+}$ and $\mathrm{Fe}^{2+}$ concentration on the $\mathrm{B}$-site. The values of $\delta$ are determined by the chemical analysis (titration method) and are given in Table (1) with the assumed values of t. The ionic radius for each site is calculated following the analysis given in [1] where

$$
\begin{aligned}
& \mathrm{r}_{\mathrm{A}}=0.8 \mathrm{r}_{\mathrm{Mn}+2}+(\mathrm{x}-\mathrm{t}) \mathrm{r}_{\mathrm{Ga}+3}+(0.2-\mathrm{x}+\mathrm{t}) \mathrm{r}_{\mathrm{Fe}+3} \\
& \mathrm{r}_{\mathrm{B}}=\left[0.2 \mathrm{r}_{\mathrm{Mn}+2}+\mathrm{t} \mathrm{r}_{\mathrm{Ga}+3}+\delta \mathrm{r}_{\mathrm{Fe}+2}+(1.8-\mathrm{t}-\delta) \mathrm{r}_{\mathrm{Fe}+3}\right] / 2
\end{aligned}
$$

where $\mathrm{r}_{\mathrm{Mn}+2}, \mathrm{r}_{\mathrm{Ga}+3}, \mathrm{r}_{\mathrm{Fe}+2}$ and $\mathrm{r}_{\mathrm{Fe}+3}$ are the ionic radii of the corresponding ion. The values of the ionic radii are taken from reference [13] where the ionic radius depends on the coordination number. Substituting the values of $r_{A}$ and $r_{B}$ into Eqn. (1) one obtains $a_{t h}$. The variation of the theoretical $a_{t h}$ and experimental $a_{0}$ lattice parameter as a function of the Ga concentration (x) is given in Fig. (2). It is clear that there is a good agreement between the theoretical and experimental values of the lattice parameters which may be in favor of our proposed cation distribution.

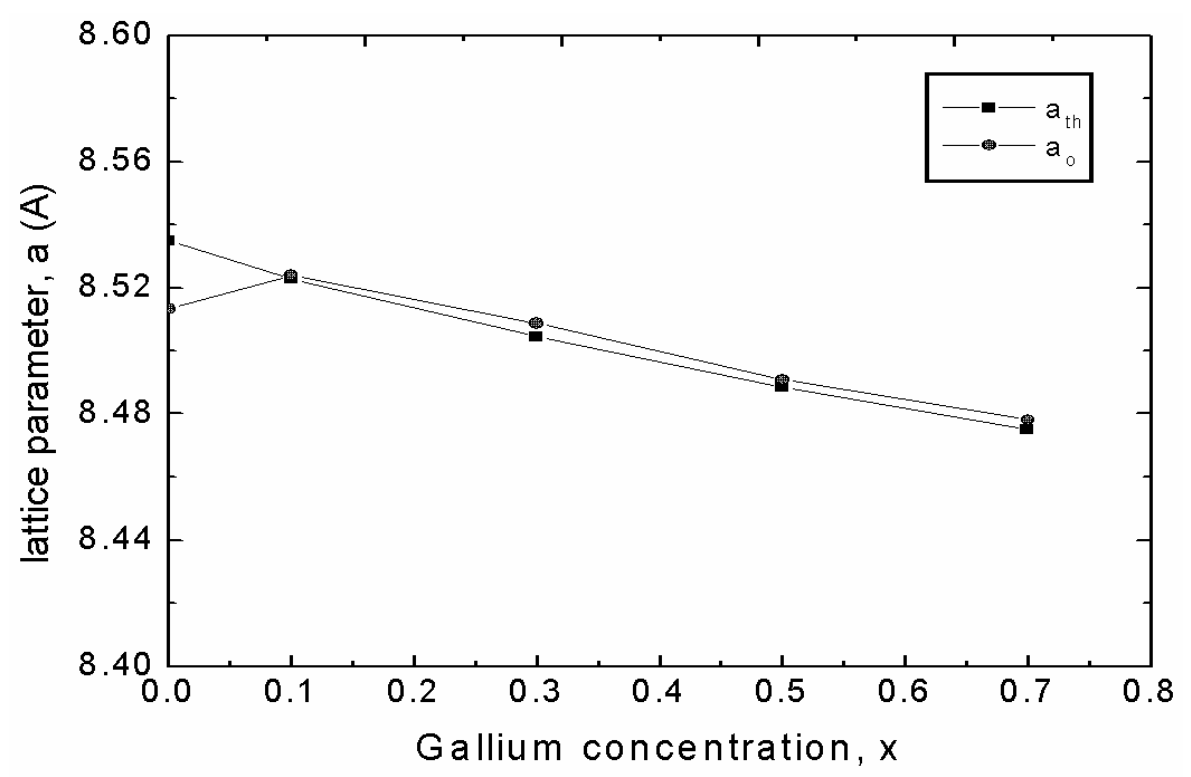

Fig. (2): Composition dependence of the theoretical $a_{\text {th }}$ and experimental $a_{0}$ lattice parameter . 
Using the experimental values of the lattice parameters, the X-ray density $\rho_{\mathrm{x}}$ was calculated for each sample according to the formula [1].

$$
\rho_{\mathrm{x}}=\frac{8 \mathrm{~W}}{\mathrm{Na}_{\mathrm{o}}^{3}}
$$

where $\mathrm{W}$ is the molecular weight of the corresponding composition and $\mathrm{N}$ is Avogadro's number. The X-ray density and the apparent density for each composition are given in Table (1). It is clear that both the X-ray density and apparent density are increased with increasing Ga concentration. It is due to the fact that the atomic weight of $\mathrm{Ga}$ (69.723) is higher than that of Fe (55.847). Moreover, according to equation (3), the decrease of the lattice parameter with increasing $\mathrm{x}$ causes $\rho_{\mathrm{x}}$ to increase. The porosity percentage was then calculated from the equation.

$$
\mathrm{P}=\left(1-\rho / \rho_{\mathrm{x}}\right) 100
$$

It is clear from Table (1) that the porosity is decreased for all Ga substituted samples, in agreement with the above discussion on the increase of the density.

\subsection{Magnetic Properties}

\section{a. Composition dependence of magnetization}

Figure (3) indicates the change of magnetization $\mathrm{M}(\mathrm{A} / \mathrm{m})$ with the applied magnetic field $\mathrm{H}(\mathrm{A} / \mathrm{m})$ at the room temperature. It is clear that, although the field is not sufficient to reach the saturation magnetization, yet it is sufficient to distinguish the effect of $\mathrm{Ga}$ substitution on $\mathrm{MnFe}_{2} \mathrm{O}_{4}$ magnetization. The dependence of magnetization on the Ga concentration (x) at a field of $2330 \mathrm{~A} / \mathrm{m}$ is shown in Fig. (4). One may notice that the magnetization decreases with increasing $\mathrm{Ga}$ concentration. As the $\mathrm{Ga}$ ion is a diamagnetic one, then the presence of $\mathrm{Ga}$ on either site will reduce the net magnetic moment of that site. As the magnetization $M$ is given by $M=M_{B}-M_{A}$, then the decrease of magnetization can not be verified unless most of the Ga ions occupy the $\mathrm{B}$ sites. If the $\mathrm{Ga}^{3+}$ ions were supposed to enter only into the A-sites, even for small $\mathrm{Ga}$ concentration, the $\mathrm{Ga}^{3+}$ ions will cause $\mathrm{Fe}^{3+}$ ions to displace from $\mathrm{A}$ to $\mathrm{B}$ sites leading to an increase in magnetization which is not observed. Thus, one concludes that most of the Ga ions must enter the B sites causing disruption of the magnetic ordering of $\mathrm{Mn}$ and $\mathrm{Fe}$ ions. Qualitatively, according to equation (2), the magnetization should decrease with increasing the gallium concentration which supports the assumed cation distribution. 


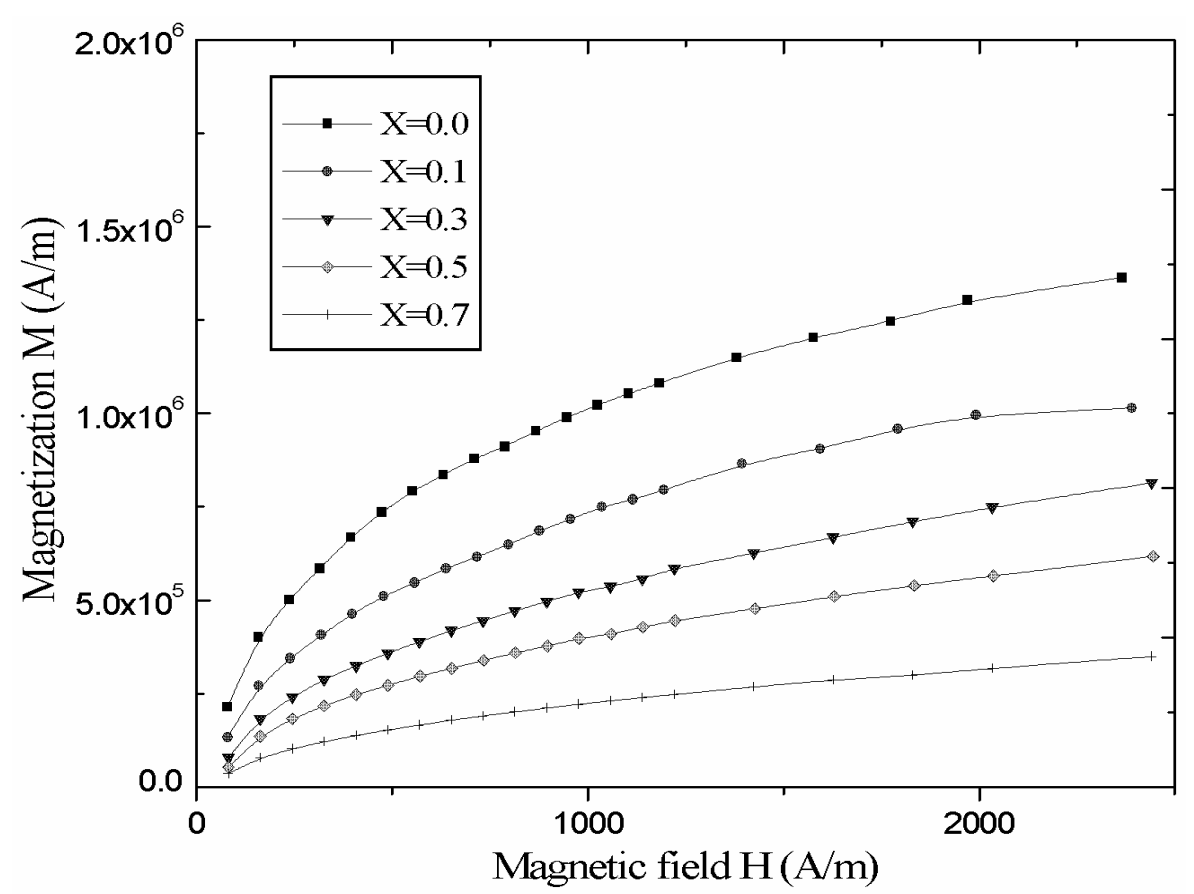

Fig. (3): Variation of magnetization $M$ with the magnetic field for different $G$ i concentrations $\mathrm{x}$.

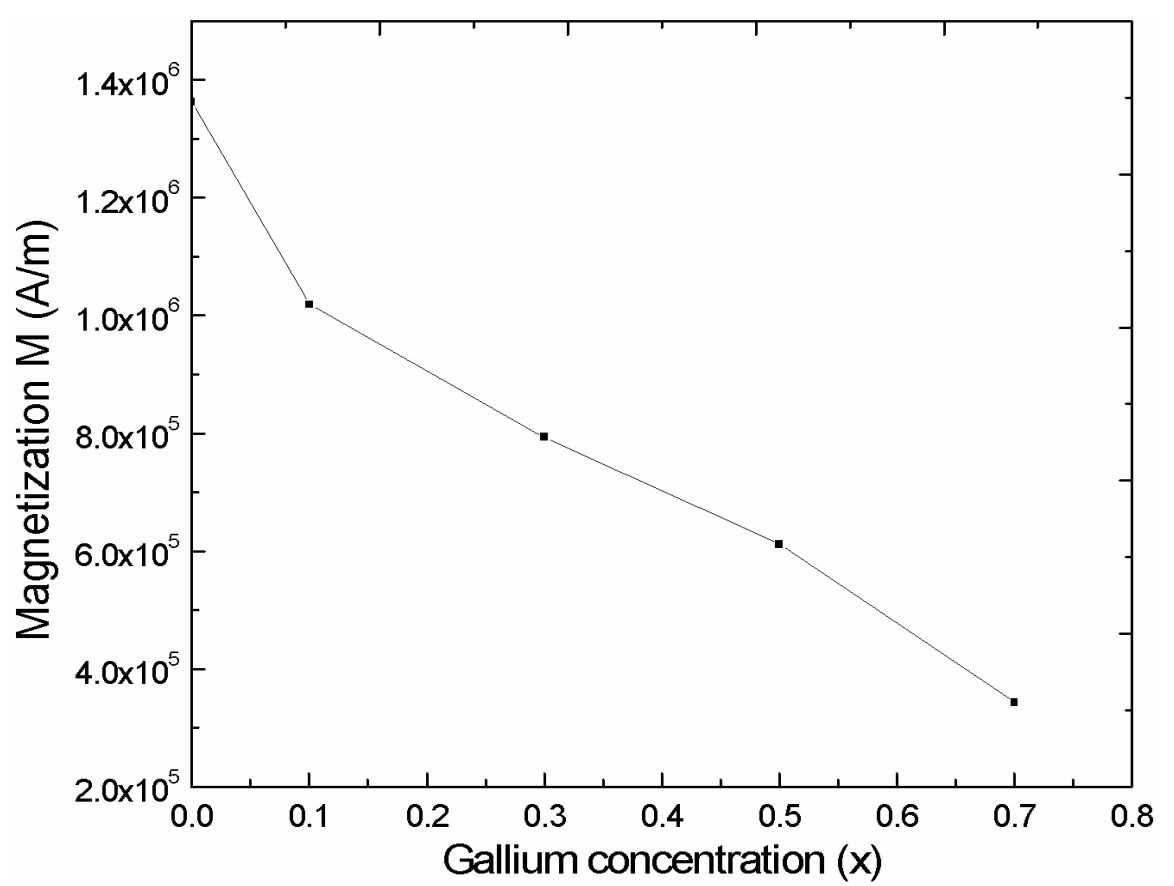

Fig. (4): Composition dependence of magnetization on Ga concentration $\mathrm{x}$. 


\section{b. Initial permeability}

Fig. (5) shows the temperature dependence of the initial permeability $\mu_{\mathrm{i}}$ for the different compositions. A pronounced broad maximum is seen in these curves far below the Curie point, except samples with $\mathrm{x}=0.5$ and 0.7. It is known that both the saturation magnetization $\mathrm{M}_{\mathrm{s}}$ and the anisotropy field $\mathrm{k}$ decrease with increasing temperature [12]. However, $\mathrm{k}$ decreases more rapidly with temperature than $\mathrm{M}_{\mathrm{s}}$. Therefore, according to equation [14].

$$
\mu_{\mathrm{i}} \cong \frac{\mathrm{M}_{\mathrm{s}}^{2} \mathrm{D}}{\sqrt{\mathrm{k}}}
$$

$\mu_{\mathrm{i}}$ must show a maximum at temperatures at which $\mathrm{k}$ vanishes where $\mathrm{D}$ is the diameter of the grain,. The disappearance of the broad maximum in samples with $\mathrm{x}=0.5$ and 0.7 may be due to a decrease of $\mathrm{Fe}^{2+}$ concentration, which is responsible for the anisotropy in ferrites. This result agrees also with the proposed cation distribution.

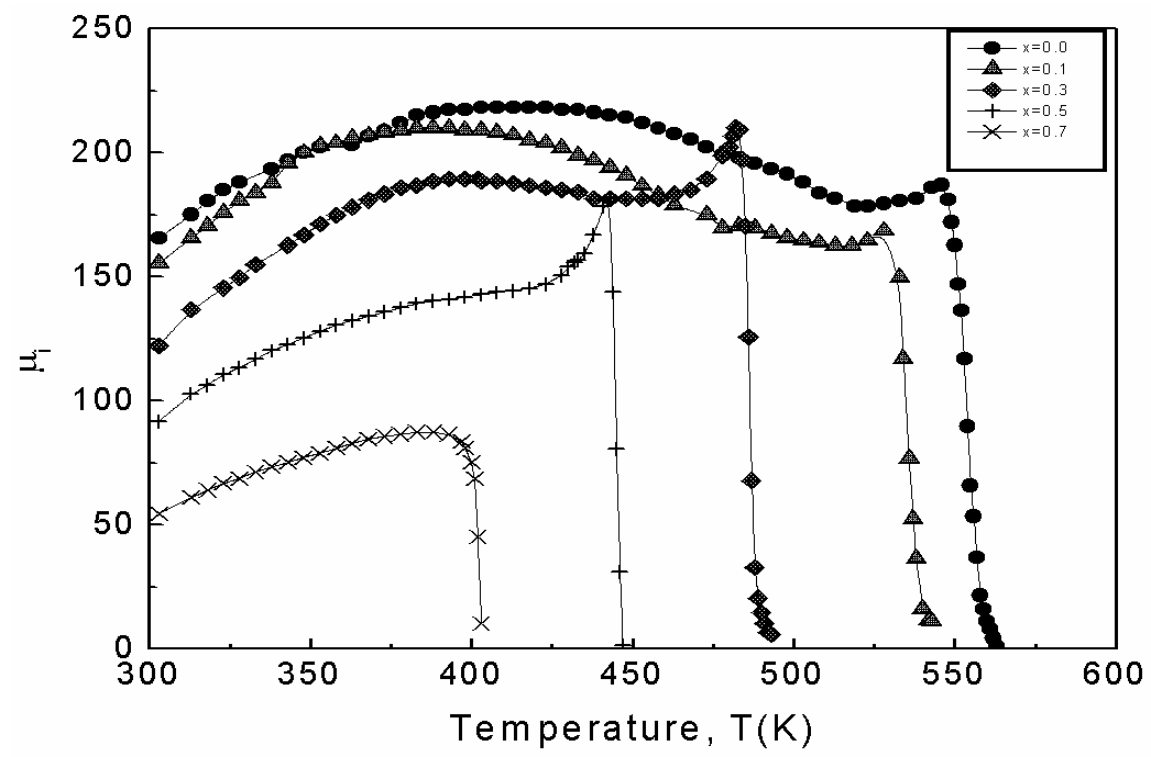

Fig. (5): Temperature dependence of the initial permeability for different Gi concentration $\mathrm{x}$.

The composition dependence of the initial permeability at $\approx 300 \mathrm{~K}$ is represented in Fig. (6). One notices that the initial permeability is decreased with increasing $\mathrm{x}$. According to equation (5), $\mu_{\mathrm{i}}$ is directly proportional to both $\mathrm{M}_{\mathrm{s}}^{2}$ and $\mathrm{D}$ and is inversely proportional to $\sqrt{\mathrm{k}}$. In the above discussion it is 
found that $\mathrm{M}_{\mathrm{s}}$ and $\mathrm{k}$ are decreased with increasing $\mathrm{x}$. To investigate the role of the grain size, the SEM was performed for samples with $\mathrm{x}=0.0,0.5$ and 0.7 and the results are shown in Fig. (7). The grain size is calculated and is found to have an average values of $17.35,21.18$ and $22.64 \mu \mathrm{m}$ for $\mathrm{x}=0.0,0.5$ and 0.7 , respectively. This means that the increase in $\mathrm{D}$ and the decrease in $\mathrm{k}$ would favor of increasing $\mu_{\mathrm{i}}$, while the decrease in $\mathrm{M}_{\mathrm{s}}$ has a reverse trend. Therefore one concludes that the decrease of magnetization dominates the effect of the grain size and the anisotropy field. This means that the decrease of $\mu_{\mathrm{i}}$ results mainly from the decrease of magnetization. Similar behavior was observed for $\mathrm{Al}_{2} \mathrm{O}_{3}$ doped $\mathrm{Mn}-\mathrm{Zn}$ ferrite [15].

The Curie temperature $T_{c}$ of each composition was determined by the intersection of the initial permeability curve with the temperature axis. The variation of $T_{c}$ with gallium concentration is shown in Fig. (6). It is clear that $T_{c}$ decreases with increasing $\mathrm{x}$. It is the expected behavior where we replaced the magnetic iron ions with the nonmagnetic $\mathrm{Ga}^{3+}$ ions. According to the assumed cation distribution, the magnetic inter-actions between the magnetic ions on the $\mathrm{B}$-sites are decreased. The reduction in $\mathrm{B}-\mathrm{B}$ and hence $\mathrm{A}-\mathrm{B}$ interactions leads to a decrease in $T_{c}$.It may be important to note the sharp decrease of $\mu_{i}$ at $T=T_{c}$ (which according to Globus) indicates that the samples have high homogeneity [16]. Such a result is consistent with the low porosity obtained for all Ga substituted samples.

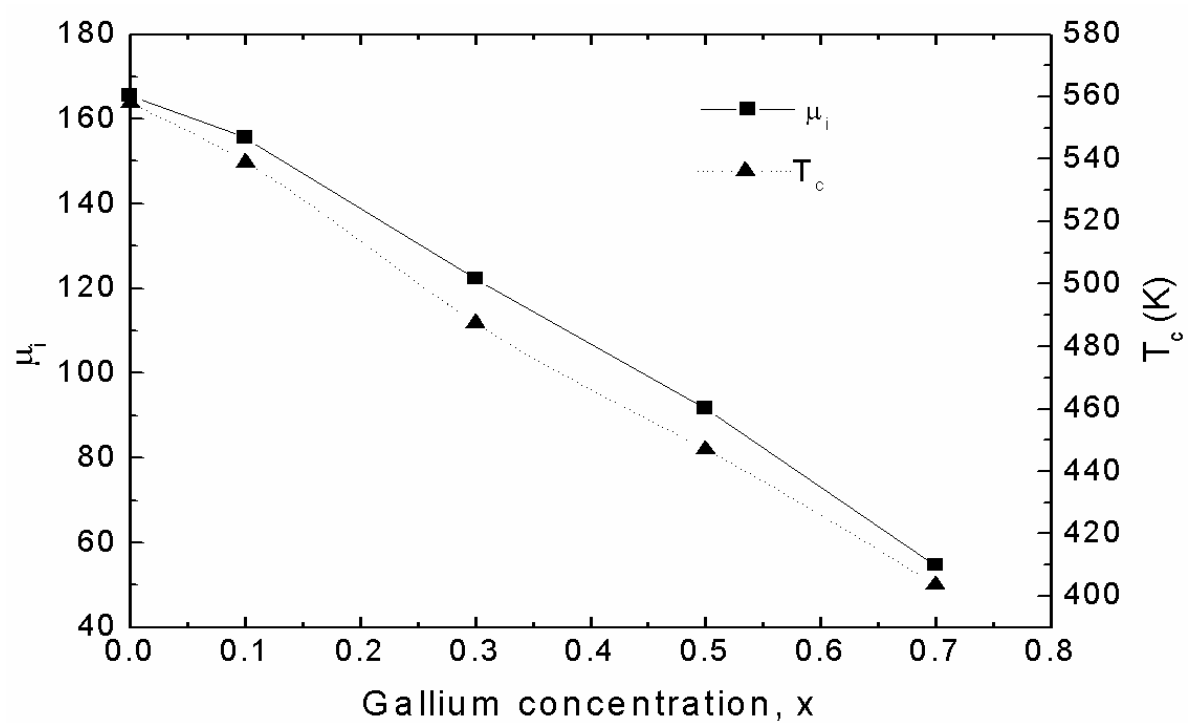

Fig. (6): Dependence of the initial permeability and Curie temperature on the G: concentration $\mathrm{x}$. 


\subsection{Electrical Resistivity}

The variation of the electrical resistivity $(\rho)$ with increasing $x$, at room temperature, is represented in Fig. (8). It is obvious that the electrical resistivity is increased rapidly with increasing $\mathrm{x}$ in spite of the decrease of the porosity. This can be explained according to the assumption that the $\mathrm{Ga}^{3+}$ ions reside mainly on B-sites. Hence the $\mathrm{Ga}^{3+}$ ions will impede the electron exchange between divalent and trivalent iron ions on B-sites. Moreover, it is known that the conduction mechanism in ferrites occurs mainly through the hopping of electrons between $\mathrm{Fe}^{2+}$ and $\mathrm{Fe}^{3+}$ in the $\mathrm{B}$ sites. Thus, the decrease of $\mathrm{Fe}^{2+}$ ion concentration with increasing $(x)$ gives a further reason for the increase of the electrical resistivity. The increase of the electrical resistivity for the investigated system gives a promising property for communication systems as the eddy current loss decreases. Therefore more details about the temperature and frequency dependence of the electrical resistivity, dielectric constant and dielectric loss will be given in the fore coming paper.
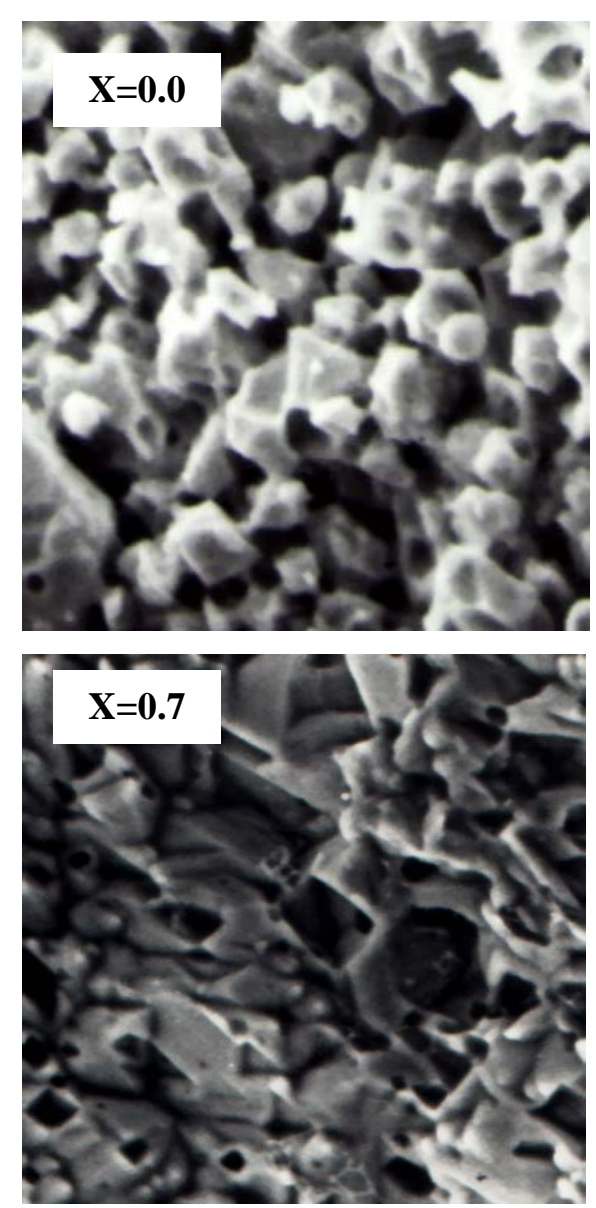

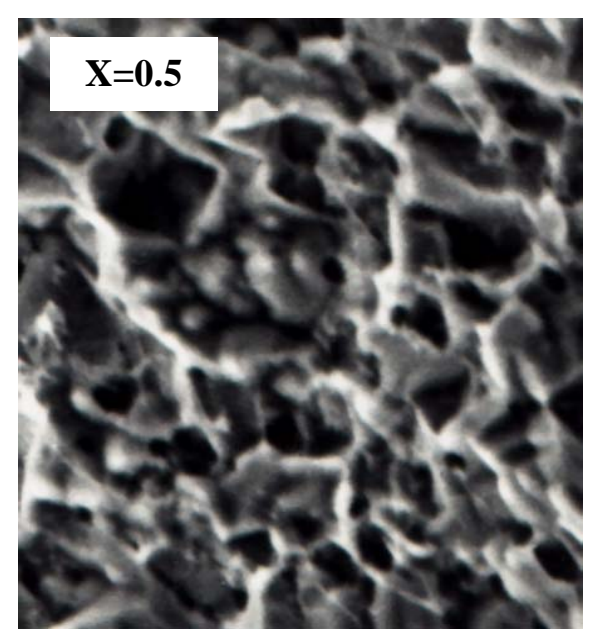

$15 \mu \mathrm{m}$

Fig. (7): Scanning electron micrograph (SEM) for $\mathrm{MnGa}_{\mathrm{x}} \mathrm{Fe}_{2-\mathrm{x}} \mathrm{O}_{4}$; $\mathrm{x}=0.0,0.5$ and 0 . 


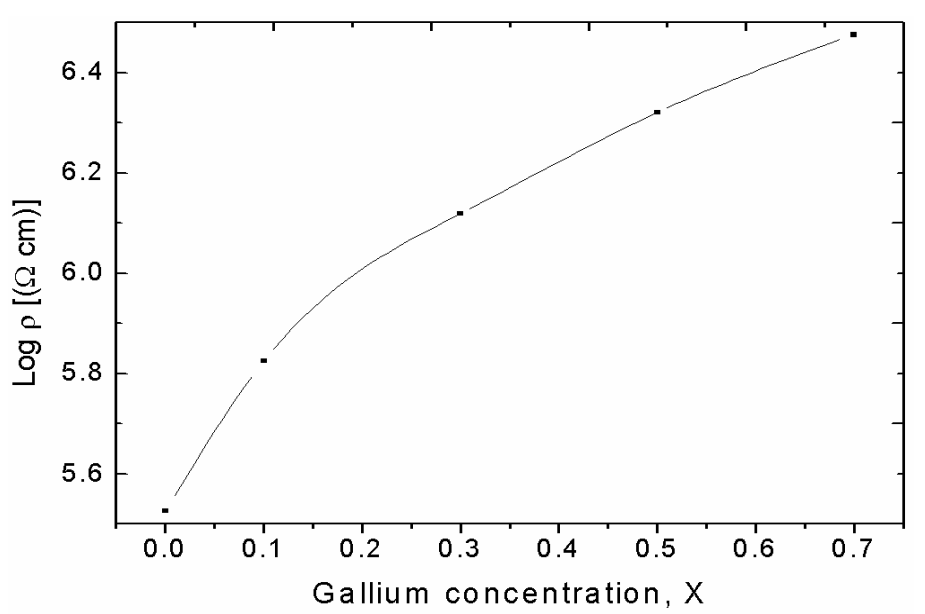

Fig.(8): Variation of the resistivity, $\log (\rho)$, with the Ga concentration $x$.

\section{Conclusion :}

1- The lattice parameter, porosity, initial permeability, magnetization and Curie temperature are decreased while the grain size, density and resistivity are increased with increasing the gallium concentration in the system $\mathrm{MnGa}_{\mathrm{x}} \mathrm{Fe}_{2-\mathrm{x}} \mathrm{O}_{4}$

2- Most of the $\mathrm{Ga}^{3+}$ ions occupy the B sites in the spinel Mn ferrite.

3- The assumed cation distribution seems to be close to the real one as it possible to interpret the magnetic and electrical properties of the investigated samples according to this distribution.

\section{References}

1. J. Smit and H.P.J. Wijn, "Ferrites", Wiley London p.140 (1959).

2. J. Tasaki and T. Izushi, J. de Phys. Colloque 38, C1-175 (1977).

3. L.R. Maxwell and S.J. Pickart, Phys. Rev. 92 (5), 1120 (1953) .

4. C.Quintanar, V. Fuentes, M. Jimenez, S. Aburto and R.Valenzuela, J. Mag. Mag. Mat. 54-57 1339 (1986) .

5. G. Dehe, J. Suwalski, E. Wieser and R. Kabisch, phys. stat. sol. (a) 65669 (1981) .

6. M. Rosenberg, P. Deppe, H.U. Janssen, V.A.M. Brabers, F.S. Li and S. Dey, J. Appl. Phys. 57 (1) 3740 (1985) .

7. M.H. Mahmoud, M.I. Abd-Elrahman, Atef M. Abdalla and A.I. Abdelmageed, phys. stat. sol. (b) 226 (2) 369 (2001).

8. S.A.J. Poltinnikov, Sov. Phys. Solid State 81144 (1966). 
9. S.A. Mazen, M.H. Abdallah, B.A. Sabrah and H.A.M. Hashem, phys. stat. sol. (a) 134263 (1992)

10. J.M. Hastings and L.M. Corliss, Phys. Rev. 104 (2) 328 (1956) .

11. M Rosenberg, P.Nicolau and I. Bunzet, phys. stat. sol. 15521 (1966).

12. K.J. Standely, "Oxide Magnetic Materials", Clarendon Press, Oxford, p.120. (1972).

13. R.D.Shannon and C.T.Prewitt, Acta Cryst.B25 925 (1969) .

14. G.C. Jain, B.K. Das, R.S. Khanduja and S.C. Gupta, J. Mat. Sci. 111335 (1976).

15. Su-il-pyun Seung-Hyum Chang, Duk-Nong Yoon and Young-Jae Shim, Am. Ceramic Soc. Bull. 64(4) 585 (1985) .

16. A. Globus, H. Pascard and V.J. Cagan, J. Physique 38 Cl-163 (1977) . 